\title{
A Factorial Analysis of Strategic Planning Dimensions among Small and Medium Enterprises and Variations in Terms of Gender in a Developing Country
}

\author{
M. Sandada \\ Faculty of Management Sciences, Vaal University of Technology \\ Private Bag X021, Vanderbijlpark, 1900 \\ Email: maxwells@vut.ac.za
}

R.I.D. Pooe

Faculty of Management Sciences, Vaal University of Technology Private Bag X021, Vanderbijlpark, 1900 Email: pooe@vut.ac.za, Fax: 0866265319

M. Dhurup

Faculty of Management Sciences, Vaal University of Technology Private Bag X021, Vanderbijlpark, 1900 Email: royd@vut.ac.za, Fax: 0866265319

Doi:10.5901/mjss.2014.v5n6p131

Abstract

The study sought to examine the strategic planning dimensions applicable among SMEs in South Africa. In addition, the study investigated whether strategic planning practices vary according to gender. A survey was conducted with 200 SMES, which were identified though convenience sampling. The results indicated that a majority of SMEs practice strategic planning. A factor analysis procedure resulted in the extraction of eight factors, namely, environmental scanning, business mission and vision, formality of strategic plans, evaluation and control, informing sourcing, strategy implementation incentives, employee participation and time horizons. No significant differences were found between SME managers/owners, based on gender with regard to the eight strategic planning dimensions. The results therefore demonstrated that sexual orientation does not play a role in one's strategic planning practices. The results of the study could assist managers in understanding the strategic paths through which a business achieves a future desired position.

Keywords: Strategic planning, business performance, small and medium enterprises.

\section{Introduction}

In South Africa and in other countries SMEs play a significant role in their economies. In order to succeed and sustain their businesses, in a dynamic environment SMEs need to engage in a strategic planning process (Dansoh, 2005). According to Jennings and Disney (2006), stable environments appear to require less planning activity, whereas unstable and competitive environments require increased planning capability and comprehensiveness, as well as greater planning flexibility. Studies have suggested that SMEs can use strategic planning as a tool to cushion them from the unstable business environments in order to ensure their survival and growth (McNamara, 1997; Bellamy 2002; Kraus, Harms \& Schwarz, 2006). Dansoh (2005) posits that strategic planning enables SMEs to be forward looking and vigilant to be able to cope with these circumstances. Small and medium enterprises, which engage in strategic planning, are more likely to be those that achieve higher sales growth, high returns on assets, higher margins on profit, higher employee growth, achieve international growth, and are less likely to fail (O'Regan \& Ghobadian, 2002; Wang, Walker \& Redmond, 2007). According to Schraeder (2002) it is important for businesses to practice strategic planning as this provides an operational framework, which allows an organization to enjoy competitive advantages and improved business performance.

In the light of the above, it is evident that there is a strong argument from the literature that SMEs need to engage in strategic planning if they are to maintain their position as key economic players. Against this background, the paper aims to investigate the strategic planning behaviour of SMEs in South Africa and to establish whether SME 
managers/owners differ significantly in their strategic planning practices considering their gender.

\subsection{SMEs and strategic planning}

SMEs are defined differently across various industries, sectors, regional economic groupings and countries. According to Ayyagari, Demirguc-Kunt and Maksimovic (2011) the term SME encompasses a diversity of definitions and measures that vary across countries and sources reporting SME statistics. Gibson and Van der Vaart (2008) argue that the absence of a uniform definition of SMEs amongst different countries has caused problems in the design, implementation, coordination and evaluation of SME-related policies. To define SMEs, various countries, regional economic groupings and multilateral institutions have adopted several different methods. Ayyagari et al. (2011) contend that generally, the number of employees, total net assets, sales and investment levels are used as criteria to define SMEs.

The South African government's general definition for SME is any business with fewer than 200 employees, where fewer than fifty workers are deemed small, and between 50 and 200, medium sized The National Small Business Amendment Act 29 of 2004). In addition, the SME has an annual turnover of R5 million, and the SME owners are involved directly in the daily management issues. Table 1 provides these classifications.

Table 1: South African SME classifications

\begin{tabular}{|c|c|c|c|c|}
\hline $\begin{array}{l}\text { Sector or sub-sector in accordance with } \\
\text { the Standard Industrial Classification }\end{array}$ & $\begin{array}{l}\text { Size or } \\
\text { Class }\end{array}$ & \begin{tabular}{|c|} 
Total full-time \\
equivalent of paid employees \\
Less than:
\end{tabular} & \begin{tabular}{|c|} 
Total annual \\
Turnover \\
Less than: \\
\end{tabular} & \begin{tabular}{|c}
$\begin{array}{c}\text { Total gross Asset value } \\
\text { (fixed property excluded) } \\
\text { Less than: }\end{array}$ \\
\end{tabular} \\
\hline Agriculture & $\begin{array}{l}\text { Medium } \\
\text { Small }\end{array}$ & \begin{tabular}{|c|}
100 \\
50
\end{tabular} & $\begin{array}{l}\mathrm{R} 4.00 \mathrm{~m} \\
\mathrm{R} 2.00 \mathrm{~m}\end{array}$ & $\begin{array}{l}\mathrm{R} 4.00 \mathrm{~m} \\
\mathrm{R} 2.00 \mathrm{~m}\end{array}$ \\
\hline Mining and quarrying & $\begin{array}{l}\text { Medium } \\
\text { Small }\end{array}$ & $\begin{array}{c}200 \\
50\end{array}$ & $\begin{array}{l}\text { R300.00 m } \\
\text { R7.50 m }\end{array}$ & $\begin{array}{l}\text { R18.00 m } \\
\text { R4.50 m }\end{array}$ \\
\hline Manufacturing & $\begin{array}{l}\text { Medium } \\
\text { Small }\end{array}$ & $\begin{array}{c}200 \\
50 \\
\end{array}$ & $\begin{array}{l}\mathrm{R} 40.00 \mathrm{~m} \\
\mathrm{R} 10.00 \mathrm{~m}\end{array}$ & $\begin{array}{l}\text { R15.00 m } \\
\text { R3.75 m }\end{array}$ \\
\hline Electricity, gas and water & $\begin{array}{l}\text { Medium } \\
\text { Small }\end{array}$ & $\begin{array}{c}200 \\
50\end{array}$ & $\begin{array}{l}\text { R40.00 m } \\
\text { R10.00 m }\end{array}$ & $\begin{array}{l}\text { R15.00 m } \\
\text { R3.75 m }\end{array}$ \\
\hline Construction & $\begin{array}{l}\text { Medium } \\
\text { Small }\end{array}$ & $\begin{array}{c}200 \\
50\end{array}$ & $\begin{array}{l}\mathrm{R} 20.00 \mathrm{~m} \\
\mathrm{R} 5.00 \mathrm{~m}\end{array}$ & $\begin{array}{l}\mathrm{R} 4.00 \mathrm{~m} \\
\mathrm{R} 1.00 \mathrm{~m}\end{array}$ \\
\hline Retail and motor trade and repair services & $\begin{array}{l}\text { Medium } \\
\text { Small }\end{array}$ & $\begin{array}{c}100 \\
50\end{array}$ & $\begin{array}{l}\text { R30.00 m } \\
\text { R15.00 m }\end{array}$ & $\begin{array}{l}\text { R5.00 m } \\
\text { R2.50 m }\end{array}$ \\
\hline $\begin{array}{l}\text { Wholesale trade, commercial agents and } \\
\text { allied services }\end{array}$ & $\begin{array}{l}\text { Medium } \\
\text { Small }\end{array}$ & $\begin{array}{c}100 \\
10\end{array}$ & $\begin{array}{l}\text { R50.00 m } \\
\text { R25.00 m }\end{array}$ & $\begin{array}{l}\mathrm{R} 8.00 \mathrm{~m} \\
\mathrm{R} 4.00 \mathrm{~m}\end{array}$ \\
\hline Catering, accommodation and other trade & $\begin{array}{l}\text { Medium } \\
\text { Small }\end{array}$ & $\begin{array}{c}100 \\
50\end{array}$ & $\begin{array}{l}\mathrm{R} 10.00 \mathrm{~m} \\
\mathrm{R} 5.00 \mathrm{~m}\end{array}$ & $\begin{array}{l}\mathrm{R} 8.00 \mathrm{~m} \\
\mathrm{R} 4.00 \mathrm{~m}\end{array}$ \\
\hline Transport, storage and communications & $\begin{array}{l}\text { Medium } \\
\text { Small }\end{array}$ & $\begin{array}{c}100 \\
50\end{array}$ & $\begin{array}{l}\text { R20.00 m } \\
\text { R10.00 m }\end{array}$ & $\begin{array}{l}\text { R5.00 m } \\
\text { R2.50 m }\end{array}$ \\
\hline Finance and business services & $\begin{array}{l}\text { Medium } \\
\text { Small }\end{array}$ & $\begin{array}{c}100 \\
50\end{array}$ & $\begin{array}{l}\text { R20.00 m } \\
\text { R10.00 m }\end{array}$ & $\begin{array}{l}\mathrm{R} 4.00 \mathrm{~m} \\
\mathrm{R} 2.00 \mathrm{~m}\end{array}$ \\
\hline Community, social and personal services & $\begin{array}{l}\text { Medium } \\
\text { Small }\end{array}$ & $\begin{array}{c}100 \\
50\end{array}$ & $\begin{array}{l}\text { R10.00 m } \\
\text { R5.00 m }\end{array}$ & $\begin{array}{l}\text { R5.00 m } \\
\text { R2.50 m }\end{array}$ \\
\hline
\end{tabular}

Source: National Small Business Amendment Act (29 of 2004)

Varied definitions of strategic planning have been suggested in the literature. Huang (2005:51) defines strategic planning as a complex and participative management technique of scanning the environment and the formulation of mission, vision and strategies in order to improve the performance of the organization, and hence its competitiveness in the market. According to Dincer, Tatoglu and Glaister (2006), the key aspects of strategic planning include the formulation of a mission statement of the enterprise, establishing the objectives, crafting and implementing the strategies, monitoring and controlling the progress in strategy implementation. In a study of the strategic planning practices of construction companies in Ghana, Dansoh (2005) found that the common elements of strategic planning are, assessing the environment, goals, course of action, allocation of resources, long-term view and competitive advantage. What is apparent from this study is that by adopting a long-term perspective, an organization is able to adapt to changes in the operating environment in a manner that increases the possibility of achieving the desired goals. 
The principal characteristics of strategic planning, as highlighted by Paterson (2009) and Fraser and Stupak (2002), are that it is a learning mechanism, it is responsive and proactive, it establishes business goals and makes decisions after a careful evaluation of monitoring of the environment. The strategic planning model suggested by David (2003) summarizes the key aspects of strategic planning. These include: developing mission and vision statements, conducting environmental analysis, formulating long term objectives, formulating strategies, implementing strategies and evaluating and controlling the performance. Desai (2000) notes that businesses must undertake strategic planning because their environments are becoming increasingly complex and unstable. This shows that strategic planning practices would therefore help them to know where they are, where they are going and how to manage. In Desai's (2000) opinion, strategic planning creates a viable link between a business' mission, vision, goals, objectives, strategic choices and resources. A number of studies have been undertaken on the benefits of strategic planning (Paris 2003; Geyer 2006; Bynum 2007; Goncalves 2009). The studies reveal that strategic planning enables businesses to identify causes and solutions to problems, understand the operating environment, define the purpose of the business, and to clarify the ambitions, values and resources of a business. The more the business practices strategic planning, the more it is able to create stability in spite of a dynamic environment. According to Fraser and Stupak (2002), strategic planning may encourage the clarification of business goals, systematic gathering of information, prioritisation of projects, teamwork, environmental responsiveness, communication of strategic intent to all stakeholders, and an improved performance. The authors are positive that the strategic planning process may strategically position a business by striking a balance between how it operates, and the requirements of the environment. Vaughn (2005) has argued that without strategic planning, a business is not clear about its mission, vision, goals and the means to achieve the goals. Strategic planning is hence, instrumental in helping the business to be focused in meeting the ever-changing needs of customers.

Joyner, Miller and Cage (2000) evaluated the strategic planning and leadership development process adopted by a school system. The aim of the research was to investigate the planning model utilised by the school, and benefits of implementing the process. The findings revealed that strategic planning served as an effective foundation for sustainable change with a view to improve continuous education in the school. Joyner et al. (2000) further assert that strategic planning increases effectiveness and collaboration, builds leadership capacity, strengthens evaluation, empowers stakeholders, builds teamwork and develops expertise among employees who participate in the process.

\subsection{Problem investigated and objectives of the study}

While strategic planning research in large organizations has been studied extensively, little attention has been paid to strategic planning of small and medium sized enterprises (O'Regan \& Ghobadian 2002). Lobontiu (2002) argues that strategic planning has not significantly filtered down to the SME sector and that those, which engage in the strategic planning exercise, have plans that are unstructured, less comprehensive and sporadic. There is little evidence of empirical research that has sought to evaluate strategic planning within the sphere of small business research (French, Kelly \& Harrison, 2004). Furthermore, Sum, Jukow and Chen (2004), also agree that despite the widespread recognition of the importance and significant contributions of SMEs, research on these small businesses remains scarce. Phillips (2000) has suggested the need for more systematic research aimed at revealing the true nature of strategic planning in SMEs. There is lack of evidence of research conducted in the Gauteng province of South Africa that has determined the strategic planning practices of SMEs.

\section{Research Methodology}

A quantitative research study was used in this study. The target population was restricted to SMEs operating in the Gauteng Province. A structured questionnaire was used by means of self-administration of questionnaires that were distributed personally by the researcher to the identified industries, which were conveniently located. The use of selfadministered questionnaires was opted for because of its cost effectiveness and ease to administer. The method also ensured a greater possibility of anonymity and greater convenience for respondents since they could complete the questionnaire at their own pace and time (Bryman \& Bell 2007). In order to identify the items to be included in the questionnaire, the study adapted the scales that were used in previous, similar studies. This was done by selecting the relevant items from the scales of previous studies by (Anderson 2000; Tse, Sin, Yau, Yee \& Chow, 2003; Falshaw, Glaister, \& Tatoglu, 2006).The structured questionnaire comprised of two sections. Section A included demographic information about the owner-managers, which are age, sex, marital status, educational background, position occupied in the business, respondent's title, as well as the business' characteristics such as, number of years in business, number of 
employees, and the type of industry to which the business belongs. This data was needed to establish a detailed profile for the sample.

Section B covered questions related to the strategic planning practices. In this section, the questionnaire asked the respondents to indicate the strategic planning practices of the business using a five-point Likert scale where $1=$ strong disagreement, $3=$ moderate agreement and $5=$ strong agreement. The questionnaire was then pilot tested with 60 respondents in order to detect weaknesses and to implement further refinement to the scale (Cooper \& Schindler 2008:296). This was undertaken to ensure that the questions were clear and captured the required information. Based on feedback from the pilot test, modifications to the questionnaire were done.

A total of 200 SMEs were identified by means of convenience sampling. Descriptive statistics such as the mean, standard deviations and frequency distributions were used to analyze the composition of the sample. Factor analysis was carried out to establish the key factors of strategic planning practices among South African SMEs. Mann Whiney U tests were used to ascertain whether there is a statistically significant difference in strategic planning behavior among owners/managers and gender.

\section{Results}

\subsection{Sample composition}

The demographic distribution of respondents indicated that out of 200 respondents, the majority of respondents 121 (60.5\%) were male and 79 (39.5\%) of respondents were female. The majority of SMEs positions are occupied by senior managers, $n=76$ (38\%) followed by junior managers $n=60(30 \%)$, respectively. In contrast to that, 42 respondents (21\%) are owners and only eight respondents (4\%) were Chief Executive Officers (CEOs), while 14 respondents (7\%) were people who occupy non-managerial positions but are involved in the strategic planning process. A highest number of owner/managers 76 (38\%) indicated that they had obtained a diploma. In contrast, 48 respondents (24\%) had attained university degree. Only $29(14.5 \%)$ of all respondents had a post-graduate degree.

\subsection{Factor analysis of strategic planning practices}

To establish the suitability of factor analysis on the data, the Bartlett's Test of Sphericity and the Kaiser-Meyer-Olkin (KMO) measure of sampling adequacy were conducted. Both of these tests confirmed the suitability factor analysis on the data. The principle component analysis (PCA) with varimax rotation was applied to the data by using a minimum eigenvalue of 1 .Varimax rotation method was used to determine how strongly correlated a measured variable was with a particular factor. The variable was supposed to load at least 0.4 on a factor because it meant that the variable belonged to that factor (Huck 2012). The rotated loading matrix results are shown in Table 2.

Table 2: Factor loading matrix and psychometric evaluation of the scale

\begin{tabular}{|c|c|c|c|c|c|c|c|c|}
\hline Variables & $\begin{array}{c}\text { Factor 1 } \\
\text { Environment } \\
\text { scanning }\end{array}$ & $\begin{array}{c}\text { Factor 2 } \\
\text { Mission } \\
\text { \& Vision }\end{array}$ & $\begin{array}{c}\text { Factor 3 Formality } \\
\text { of strategic } \\
\text { planning }\end{array}$ & $\begin{array}{c}\text { Factor 4 } \\
\text { Evaluation } \\
\text { and control }\end{array}$ & $\begin{array}{c}\text { Factor 5 } \\
\text { Source } \\
\text { of information }\end{array}$ & $\begin{array}{c}\text { Factor 6 Strategy } \\
\text { implementation } \\
\text { incentives }\end{array}$ & $\begin{array}{c}\text { Factor 7 } \\
\text { Employee } \\
\text { participation }\end{array}$ & $\begin{array}{c}\text { Factor 8 } \\
\text { Time } \\
\text { horizon }\end{array}$ \\
\hline 1 & 0.306 & 0.029 & 0.203 & 0.075 & 0.639 & -0.034 & -0.1 & 0.067 \\
\hline 2 & 0.026 & 0.054 & 0.038 & 0.122 & 0.755 & 0.249 & 0.106 & -0.09 \\
\hline 3 & 0.538 & 0.298 & 0.351 & 0.122 & -0.031 & 0.143 & 0.107 & 0.037 \\
\hline 4 & 0.762 & 0.32 & 0.149 & 0.093 & -0.007 & 0.122 & 0.129 & 0.026 \\
\hline 5 & 0.803 & 0.194 & 0.133 & 0.142 & 0.184 & 0.062 & 0.147 & 0.098 \\
\hline 6 & 0.757 & 0.138 & 0.117 & 0.256 & 0.223 & -0.076 & 0.033 & 0.15 \\
\hline 7 & 0.778 & 0.162 & -0.002 & 0.016 & 0.189 & 0.184 & 0.203 & 0.115 \\
\hline 8 & 0.281 & -0.004 & 0.248 & 0.567 & 0.086 & 0.177 & 0.003 & -0.082 \\
\hline 9 & 0.294 & -0.021 & 0.262 & 0.589 & 0.018 & 0.21 & 0.07 & 0.149 \\
\hline 10 & 0.06 & 0.212 & 0.033 & 0.782 & 0.246 & -0.025 & 0.016 & 0.074 \\
\hline 11 & 0.252 & 0.194 & -0.021 & 0.494 & 0.074 & 0.325 & 0.357 & 0.244 \\
\hline 12 & 0.474 & 0.015 & 0.272 & 0.384 & 0.069 & 0.256 & 0.232 & 0.153 \\
\hline 13 & 0.221 & 0.023 & 0.133 & 0.181 & 0.158 & 0.761 & 0.005 & -0.057 \\
\hline 14 & 0.061 & 0.07 & 0.084 & 0.094 & 0.062 & 0.825 & -0.028 & 0.218 \\
\hline
\end{tabular}




\begin{tabular}{|c|c|c|c|c|c|c|c|c|}
\hline 15 & 0.505 & 0.223 & 0.12 & 0.115 & 0.225 & 0.151 & 0.117 & 0.15 \\
\hline 16 & 0.306 & 0.029 & 0.203 & 0.075 & 0.639 & -0.034 & -0.1 & 0.067 \\
\hline 17 & 0.026 & 0.054 & 0.038 & 0.122 & 0.755 & 0.249 & 0.106 & -0.09 \\
\hline 18 & 0.538 & 0.298 & 0.351 & 0.122 & -0.031 & 0.143 & 0.107 & 0.037 \\
\hline 19 & 0.762 & 0.32 & 0.149 & 0.093 & -0.007 & 0.122 & 0.129 & 0.026 \\
\hline 20 & 0.803 & 0.194 & 0.133 & 0.142 & 0.184 & 0.062 & 0.147 & 0.098 \\
\hline 21 & 0.757 & 0.138 & 0.117 & 0.256 & 0.223 & -0.076 & 0.033 & 0.15 \\
\hline 22 & 0.778 & 0.162 & -0.002 & 0.016 & 0.189 & 0.184 & 0.203 & 0.115 \\
\hline 23 & 0.281 & -0.004 & 0.248 & 0.567 & 0.086 & 0.177 & 0.003 & -0.082 \\
\hline 24 & 0.294 & -0.021 & 0.262 & 0.589 & 0.018 & 0.21 & 0.07 & 0.149 \\
\hline 25 & 0.06 & 0.212 & 0.033 & 0.782 & 0.246 & -0.025 & 0.016 & 0.074 \\
\hline 26 & 0.252 & 0.194 & -0.021 & 0.494 & 0.074 & 0.325 & 0.357 & 0.244 \\
\hline 27 & 0.474 & 0.015 & 0.272 & 0.384 & 0.069 & 0.256 & 0.232 & 0.153 \\
\hline 28 & 0.221 & 0.023 & 0.133 & 0.181 & 0.158 & 0.761 & 0.005 & -0.057 \\
\hline 29 & 0.061 & 0.07 & 0.084 & 0.094 & 0.062 & 0.825 & -0.028 & 0.218 \\
\hline 30 & 0.505 & 0.223 & 0.12 & 0.115 & 0.225 & 0.151 & 0.117 & 0.15 \\
\hline 31 & 0.306 & 0.029 & 0.203 & 0.075 & 0.639 & -0.034 & -0.1 & 0.067 \\
\hline 32 & 0.026 & 0.054 & 0.038 & 0.122 & 0.755 & 0.249 & 0.106 & -0.09 \\
\hline Eigenvalues & 10.40 & 2.24 & 1.74 & 1.62 & 1.44 & 1.30 & 1.11 & 1.09 \\
\hline \%of variance & 17.36 & 10.42 & 9.80 & 7.02 & 6.17 & 5.81 & 5.74 & 5.52 \\
\hline Cumulative\% & 17.36 & 27.78 & 37.58 & 44.61 & 50.78 & 56.59 & 62.33 & 67.85 \\
\hline Cronbach $\alpha$ & 0.91 & 0.86 & 0.84 & 0.71 & 0.64 & 0.69 & 0.73 & 0.71 \\
\hline
\end{tabular}

The eigenvalues, percentage of variance explained by each factor, and the cumulative percentage of variance for the factor structures are reported in Table 2. Eight factors accounted for $67.85 \%$ of the overall explained variance. These factors included environmental scanning (9 items), business mission and vision (4 items), formality of strategic planning (5 items), evaluation and control (4 items), source of information about the environment (3 items), strategy implementation incentives (2 items), employee participation in strategic planning (2 items), and time horizon of strategic planning ( 2 items). The next section addresses the naming and interpretation of the factors.

\subsection{Non-parametric Mann-Whitney U test - Strategic planning dimensions and gender}

A non-parametric method of Mann-Whitney $U$ Test was conducted to determine if there was evidence of any differences in terms of gender across the eight factors of strategic planning practices. A non-parametric statistical method was used because it is suitable for ranked and unevenly distributed data in terms of the various sector categories (Weiers 2008). The Mann-Whitney $U$ test assumes that the data values are independent of each other, and that the samples are drawn from the same distribution (Sharpe, Veaux \& Velleman 2012). The Mann-Whitney U test is reported in Table 3.

Table 3: Mann-Whitney U test- Eight strategic planning dimensions across gender

\begin{tabular}{lcc}
\hline \multicolumn{1}{c}{ Strategic planning dimensions } & Z-value & Significance value \\
\hline Environmental scanning & -0.978 & 0.328 \\
Business mission and vision & -1.821 & 0.069 \\
Formality of strategic planning & -0.361 & 0.718 \\
Evaluation and control & -0.399 & 0.690 \\
Sources of information & -1.589 & 0.112 \\
Strategy implementation incentives & -0.301 & 0.764 \\
Employee participation & -1.671 & 0.095 \\
Time horizon & -0.560 & 0.560 \\
Significant level $=\mathbf{0 . 0 5}$ & & \\
\hline
\end{tabular}

The Mann-Whitney $U$ test show that there were no significant difference between the eight strategic planning dimensions and gender as the $p$-values were $>0.05$. 


\section{Discussion of Results}

Factor one labeled environmental scanning explained $17.36 \%$ of the variance. The factor comprises nine items. High loadings in this factor includes variables relating to value chain analysis, Porter's five forces, benchmarking, Political, Economic, Social and Technology (PEST) analysis, environmental scanning about social changes, and environmental scanning about economic changes. In today's high levels of competition, uncertainty and turbulence require businesses to scan the environment in order to detect the market changes so as to effectively respond in a way that improves their competitiveness (Karami 2008). This indicates that scanning the environment is crucial because this will enable a business to adapt to the dictates of the continuously changing market. The importance of environmental scanning as a factor of strategic planning was confirmed by several studies. Jorosi's (2008) study of the environmental scanning practices of Botswana's small and medium sized manufacturing enterprises also confirmed that organizations scan the environment in order to make informed decisions. For South Africa, a study by Neneh and Van Zyl (2012) found that about 53 percent of SMEs engage in strategic planning practices in order to achieve long-term survival through environmental scanning.

Factor two labeled business mission and vision, explained $7.24 \%$ of the variance. The factor consists of four items. High factor loadings on this factor relates to the presence of vision and mission statements, awareness of the mission of the business and awareness of the vision of the business. In an analysis of the role of strategic planning in the performance of small service businesses, French et al. (2004) affirm the importance of business mission and vision as a factor of strategic planning. A mission and vision statement enhances business performance because it reminds employees of key organizational values that provide general guideline to diagnoses and solution to problems. It also ensures that the organization is visionary and has concern for customers and other stakeholders when conducting its business operations (Bart \& Hupfer 2004).

The third factor labeled formality of strategic planning, explained $9.80 \%$ of the variance. High factor loadings on this factor pertains to the understanding of customers and their needs, continuous collection of information about the business environment, environmental scanning about technological advances, flexibility of the strategic planning process and the use of formal methods to present a strategic plan. Formality of strategic planning describes the extent to which the strategic plan is presented in written form. The respondents indicated that they present the strategic plan in facts and figures, and that the plan can be adjusted if necessary. Pellissier and Kruger (2011) report the use of a formalized strategic plan in a study of the practice of strategic management within the South African long-term insurance industry. The presence of this factor in the study indicates that SMEs acknowledge the necessity of formalizing the strategic plan.

The fourth factor labeled evaluation and control, accounted for $7.02 \%$ of the explained variance. High factor loadings on this factor relate to the extent to which SMEs owners/managers schedule regular to monitor progress, periodic reviews to monitor progress and use of various forms of communications to provide feedback to employees. The inclusion of this factor in the strategic planning process of SMEs resonate with the affirmations by Ehlers and Lazenby (20075) that through continuous monitoring and control, SMEs are able to sustain an competitive edge. The basic thought is that evaluation and control monitors strategy implementation in order to identify the fit between strategies and objectives (David 2003). The evaluation and control construct suggests that SMEs are likely to monitor their progress in strategy implementation and take corrective action to correct deviations from the standards set.

The fifth factor labeled source of information, accounted for $6.17 \%$ of the explained variance. High loadings on this factor relate to the media and other sources of information on current trends and changes in the business environment, trade meetings as the main source of information, and observing competitors in the environment. SMEs rely on internal and external sources of information about the environment. Jorosi (2008) affirms that internal and external sources are used by businesses to track changes in the environment. Popoola's (2000) study of the scanning behaviour in Nigerian banks also supported the use of internal and external sources of market changes.

The sixth factor labeled strategy implementation incentives consisted of variables relating to incentives that are used to motivate employees in the implementation process and explained $5.81 \%$ of the variance. This factor consists of two items which include profit sharing to motivate employees and non-monetary rewards as incentives for strategy implementation. This suggests that SMEs use rewards to motivate employees for goal attainment. Ehlers and Lazenby (2007) support the use of this construct by stating that motivating rewards for employees are a necessary condition for business to implement strategies successfully. Thus, when employees are incentivized, the rewards may generate successful strategy implementation. Ehlers and Lazenby (2007), further posit that one of the barriers to successful strategy implementation is the people barrier where only 25 percent of managers use rewards in strategy implementation. The view is consistent with Okumus's (2003) strategy implementation framework, which recommends incentives as a key factor to successfully implement strategies. 
The seventh factor labeled employee participation in the strategic planning process which accounted for $5.74 \%$ of the explained variance. The items include supervisors' and employees participation in formulating business mission, vision, objectives and strategies jointly within the organization. A participative strategic planning process is encouraged because it leads unity of purpose, cooperation, and employee motivation (Gadiesh \& Gilbert 2001; Speculand 2009). Elbana (2008) affirms that in a participative strategic planning process, temporary committees comprising employees of different ranks should be formed for consultation purposes and to drive the strategic planning process.

The eighth factor labeled time horizons explained $5.52 \%$ of the variance. This factor comprised two variables, which relate to time frames, medium and long-term planning. Most of the SMEs indicated that they make use of three to four year strategic plans thereby inferring that generally the owners/managers have a medium term focus for their businesses. Confirming the importance of this construct, Dincer et al. (2006) also found that time horizons is essential in the strategic planning process.

Mann-Whitney $U$ tests regarding the eight strategic planning dimensions and gender showed that that there is no statistical significant differences among male and female owners/managers of SMEs. This complies with a research study by Manganyi (2001) which found no statistically significant difference in the factor mean scores between male and female principals with regard to strategic planning in South African schools. This may be due to the perceived importance of strategic planning on the performance of business by SME owners/managers in today's dynamic business environment.

\section{Reliability and Validity}

The internal consistency of strategic planning dimensions was established by computing Cronbach's alpha coefficients. The overall coefficient alpha for the eight strategic planning scales was 0.93 which was above the acceptable benchmark of 0.70 (Bryman \& Bell, 2007:164). Content validity was ascertained by pre-testing the questionnaire and a review of the questionnaire by management academics and a statistician. In addition, a pilot test was undertaken where changes were made to the questionnaire regarding the deletion of items, addition of items, rewording and rephrasing of questions. Construct validity of the scale was assessed through the factor analysis procedure to determine what percentage of variance is explained by each factor. The results indicate that the eight factors accounted for approximately sixty eight percent of the variance explained thus inferring construct validity.

\section{Conclusion and Implications for Further Research}

The pertinent dimensions that characterise the strategic planning practices of SMEs that emerged in this study also emerged in studies by other scholars for example, employee participation in strategic planning process (Elbana 2008), environmental scanning (Jorosi 2008), and business mission and vision (Mazzarol, Rebound, \& Soutar, 2009). This study suggests that if businesses practice strategic planning, they will be able to assess their environment, adjust their strategies, cushion themselves from the dynamic environment, and hence improve their performance. All the strategic planning components (environmental scanning, mission and vision statement, formality of strategic planning, sources of information about the environment, strategy evaluation and control, strategy implementation incentives, employee participation in the strategic planning process and the time horizon of strategic planning) need to be enhanced in order to improve their performance. SMEs owners/managers should, therefore, make every effort to practice more strategic planning activities to enhance their competitiveness.

Furthermore, this study focussed only on SMEs that are operating in Gauteng province of South Africa. Future research could replicate the study in other provinces in order to test the validity and reliability of the scale. Another prospect for future research is to conduct comparative studies of the relationship between strategic planning and business performance, for example between SMEs in a developed and an emerging country, or between privately owned large businesses and public sector enterprises. Other institutions, such as family businesses and non-governmental organizations that may have different strategic planning practices may also be examined. On the other hand, this study examined SMEs falling under different sectors. It will be an interesting extension of the study if future research examines the strategic planning and business performance relationship within a specific sector, as those findings will be more focussed and relevant to that specific industry.

\section{References}

Andersen, T.J. (2000). Strategic planning, autonomous actions and corporate performance. Long Range Planning, 33: $184-200$.

Ayyadari, M., Demirguc-Kunt, A. \& Maksimovic, V. (2011). Small vs young firms across the world: contributions to employment, job 
creation, and growth, Policy Research Working Paper 5631. World Bank, DC, Washington.

Bart, C.K. \& Hupfer, M. (2004). Mission statements in Canadian hospitals. Journal of Health Organization and Management, 18(2): 92110.

Bellamy, L. (2002). The strategic planning paradox: Do small firms benefit? ISBA National Small Firms Policy and Research Conference Proceedings: 71-76. Leeds.

Bryman, A. \& Bell, E. (2007). Business Research Methods. 2nded. Oxford: University Press.

Bynum, C. (2007). GIS Strategic planning: a paper presented at Kentury GIS Conference in Kentury in 2007. Kentury: 1-27.

Dansoh, A. (2005). Strategic planning practice of construction firms in Ghana. Construction Management and Economics, 23: 163-168, February.

David, F.R. (2003). Strategic management: concepts and cases. New Jersey: Pearson.

Desai, A. B. (20000. Does strategic planning create value? The stock market's belief. Management Decision Journal, 38(10): 685-693.

Dincer, O., Tatoglu, E. \& Glaister, K.W. (2006). The strategic planning process: Evidence from Turkish firms. Management Research News, 29(4):206-219.

Ehlers, T\& Lazenby, K. (2006). Strategic management: Southern African concepts and cases. Pretoria: Van Schaik Publishers.

Elbanna, S. (2008). Planning and participation as determinants of strategic planning effectiveness: evidence from the Arabic context. Management Decision, 46(5): 779-796.

Falshaw, J.R., Glaister, K.W. \& Tatoglu, E. (2006). Evidence on formal strategic planning and company performance. Management Decision Journal, 44(1):9-30.

Fraser, D.L. \& Stupak, R.J. (2002). A synthesis of the strategic planning process with the principles of learning, leading and linking. International Journal of Public Administration, 25(9): 1199-1220.

French, J. S., Kelly, S. \& Harrison, J. (20040.The role of strategic planning in the performance of small professional services firms. Journal of Management Development, 23(8):765-776.

Gadiesh, O. \& Gibert, J.L. (2001). Transforming corner office strategy into frontline action. Harvard Business Review, 16-25. May.

Geyer, Y. (2006). Strategic planning: handbook series for community-based organizations. Pretoria: Institute for democracy in South Africa

Gibson, T. \&Van der Vaart, H.J. (2008). Defining SMEs: A less imperfect way of defining small and medium enterprises in developing countries. Brookings Discussion Paper.

Goncalves, H, S. (2009). Proposal of a strategy model planning aligned to the balanced scorecard and the quality environments. The TQM Journal, 21(5): 462-472.

Huang, C. J. (2006). Strategic planning and dysfunction: the dark side of mandating a formal planning system. Soochow Journal of Political Science, 22: 47-71.

Huck, S.W. (2012). Reading Statistics and Research.6th ed. Boston. Pearson Education.

Jennings, D. \& Disney, J. (2006). Designing the strategic planning process: does psychological type matter. Management Decision Journal, 44(5):598-614.

Jorosi, B.N. (2008). Environmental scanning in Botswana's SMEs: a study of the manufacturing industry. Libri, 58: 224-233.

Joyner, L.M., Miller, W.J. \& Cage, B.N. (2000). Strategic planning: a foundation for sustaining change. National Forum of Special Education Journal, 9E: 8-12.

Karami, A. (2008). An investigation on environmental scanning and growth strategy in high tech small and medium sized enterprises: paper read at the high technology firms conference held at the University of Twente between 21 and 23 May 2008. Twente: 1-17.

Kraus, S., Harms, R. \& Schwarz, E.J. (2006). Strategic planning in smaller enterprises- new empirical findings. Management Research News, 29(6): 334-344.

Lobontiu, G. (2002). Strategies and strategic management in small business. MPP working paper, 15. Copenhagen: Copenhagen Business School, Department of Management, Politics and Philosophy.

Manganyi, M.M. (2001). Strategic planning as an aspect of school management: Implication for whole school development. Master of education mini dissertation. School of Educational management. Rand Africaans University. South Africa.

Mazzarol, T., Rebound, S. \& Soutar, G.N. (2009). Strategic planning in growth oriented small firms. International Journal of Entrepreneurial Behaviour and Research, 15(4): 320-345.

Mcnamara, C. (2007). Strategic planning in non-profit or for profit organizations. Field guide to non- profit strategic planning facilitation.3rd ed. Minnesota: Authenticity Consulting, LLC.

Neneh, N.B. \& Vanzyl, J. (2012). Towards establishing long term surviving small and medium enterprises (SMEs) in South Africa: An entrepreneurial approach. African Journal of Business Management,6(28):8327-8343.

Okumus, F. (2003). A framework to implement strategies in organizations. Management Decision Journal, 41(9):871-882.

O'regan, N. \& Ghobadian, A. (2004).The importance of capabilities for strategic direction and performance. Management Decision, 42(2): 292-312.

Paris, K.A. (2003). Strategic planning in the University. University of Wisconsin System Board of Regents, USA.

Paterson, A. (2009). A review of strategic planning practices that may be applied by the South African National Planning Commission. Development planning division working paper series No. 6. Development Bank of Southern Africa.

Pellissier, R. \& Kruger, J.P. (2011). A study of strategic intelligence as a strategic management tool in the long-term insurance industry in South Africa. European Business Review, 23(6):609-631.

Phillips, P. (2000). The strategic planning/finance interface: does sophistication really matter? Management Decision, 38(8): 541-549. 
Popoola, S.O. (2000). Scanning the environment for competitive advantage: a study of corporate banking managers in Nigeria. Libri, 50: 210-216.

Republic Of South Africa. 2004. National Small Business Amendment Act(29 of 2004), Government Gazette 474 No. 27101 , available at:www.info.gov.za/gazette/acts (accessed 10/06/2009).

Schraedr, M. (2002). A simplified approach to strategic planning. Practical considerations and illustrated example. Business Process Management Journal, 8(1): 8-18.

Sharpe, N.R., De Veaux, R.D. \& Vellem, P.E. (2012). Business Statistics.2nd ed. Boston: Pearson Education.

Speculand, R. (2009). Six necessary mind shifts for implementing strategy. Business Strategy Series, 10(3): 167-172.

Sum, C., Jukow, L. \& Chen, S. (2004).Taxonomy of operations strategies of high performing small and medium enterprises in Singapore. International Journal of Operations and Production Management 24 (3):321-345.

Tse, A. C.B., Sin, L.Y.M., Yau, O. H. M., Lee, J. S. Y. \& Chow, R. (2003). Market orientation and business performance in a Chinese business environment. Journal of Business Research, 56: 227-239.

Vaughn, A.L. (2005). Strategic planning: management assistance models for the nonprofit sector. Masters of Public Administration dissertation. A school of Public Administration and Policy.

Wang, C., Walker, E.A. \& Redmond, J. (2007). Explaining the lack of strategic planning in SMEs: the importance of owner motivation. International Journal of Organizational Behaviour, 12(1): 1-16.

Weiers, R.M. (2008). Introduction to Statistics. $6^{\text {th }}$ ed. Mason: Thompson Western. 
